\title{
Influence of weight loss on heart rate variability in dogs
}

\author{
Influência da perda de peso na variabilidade da freqüência \\ cardíaca em cães
}

\author{
Mário dos Santos Filho'*, Daniel Carvalho Hainfellner ${ }^{2}$, Nathália Marques de Oliveira Lemos ${ }^{3}$, \\ Camila de Oliveira Ferreira Mendes ${ }^{4,5}$, Patrícia Malandrim6, Jenifer Marques Campos ${ }^{7}$, Sophie Ballot ${ }^{8}$, \\ Priscila Cardim de Oliveira9 $\&$ Jonimar Pereira Paiva ${ }^{10}$
}

'Veterinary, MSc, Doctoral Student. Programa de Pós-graduação em Medicina Veterinária - Ciências Clínicas, Universidade Federal Rural do Rio de Janeiro - UFRRJ, Seropédica, RJ, Brasil

2Veterinary, MSc, Autonomous. Rio de Janeiro, RJ, Brasil

Veterinary, Master's Degree Student. Programa de Pós-graduação em Medicina Veterinária, Universidade Federal Rural do Rio de Janeiro - UFRRJ, Seropédica, RJ, Brasil

${ }^{4}$ Young Veterinary Scholar. Programa Jovem Veterinário Nestlé Purina, Seropédica, RJ, Brasil

${ }^{5}$ Veterinary Student. Instituto de Veterinária, Universidade Federal Rural do Rio de Janeiro - UFRRJ, Seropédica, RJ, Brasil

${ }^{6}$ Veterinary, Autonomous. São João da Boa Vista, SP, Brasil

`Veterinary, Autonomous. Barbacena, MG, Brasil

\&Veterinary Student, PIBIC-CNPq Scholarship Holder. Universidade Federal Rural do Rio de Janeiro - UFRRJ, Seropédica, RJ, Brasil

'Veterinary, MSc, Doctoral Student. Programa de Pós-graduação em Ciência Veterinária, Universidade Federal Rural do Rio de Janeiro - UFRRJ, Seropédica, RJ, Brasil

${ }^{10}$ Veterinary, Dsc. Departamento de Medicina Veterinária e Cirurgia, Instituto de Veterinária, Universidade Federal Rural do Rio de Janeiro - UFRRJ, Seropédica, RJ, Brasil

tDeceased

\begin{abstract}
The autonomic nervous system (ANS) plays a role in the regulation of the cardiovascular system through sympathetic and parasympathetic modulations, which act in an associated way in the regulation of homeostasis. This regulation exercised by the ANS is determined by numerous factors including breathing, stress, temperature, blood pressure and physical activity. Cardiac nerve regulation is influenced by obesity, but the autonomic response present in this disorder has not yet been elucidated. It is known that a $10 \%$ increase in body fat is able to lead to a decrease in parasympathetic action and an increase in heart rate. Heart Rate Variability (HRV) allows the evaluation of autonomic heart modulation through the ventricular depolarization intervals to the electrocardiogram (ECG), and provides information on the relationship and contribution of the ANS to the neural influence of heart rate control. The objective of the present study was to evaluate the HRV by means of an electrocardiographic examination in obese dogs with Body Condition Score (BCS) 8/9 and 9/9, comparing with HRV of the same animals, after therapy with therapeutic ration in the period of 6 months, as well as the comparison with control group with lean animals. With the results obtained in the present study, it can be inferred that probably the imbalance in the autonomic activity due to obesity in dogs is not the same as in humans and that a greater understanding of this regulation in these animals is necessary, especially considering their vagotonia. The diet program based on low-calorie ration reached approximately $10 \%$ and $20 \%$ of weight reduction after two and six months, respectively. Obesity raises HRV by increasing parasympathetic activity in the autonomic regulation of the heart in dogs.
\end{abstract}

Keywords: autonomic balance, obesity, dogs.

\section{Resumo}

O sistema nervoso autônomo (SNA) exerce papel de regulação do sistema cardiovascular por meio da modulação simpática e parassimpática, que atuam de maneira associadas na regulação da homeostase (Pumprla et al., 2002). Este balanço exercido pelo SNA é determinado por inúmeros fatores incluindo a respiração, estresse, temperatura, pressão sanguínea e atividade física (Vanderlei et al., 2009). A regulação nervosa cardíaca sofre influência da obesidade, mas ainda não foi esclarecida qual a resposta autonômica presenteneste distúrbio (Pascon, 2009). Sabe-se que o aumento de 10\% da gordura corpóreaé capaz de levar à diminuição da ação parassimpática e aumento da frequência cardíaca (Van Vliet et al., 1995). A Variabilidade da Frequência Cardíaca (VFC) permite avaliar a modulação autonômica sobre o coração, por meio dos
How to cite: Santos Filho, M., Hainfellner, D. C. Lemos, N. M. O., Mendes, C. O. F., Malandrim, P., Campos, J. M., Ballot, S., Oliveira, P. C., \& Paiva, J. P. (2019). Influence of weight loss on heart rate variability in dogs. Brazilian Journal of Veterinary Medicine, 411,e98119. doi: 10.29374/2527-2179. bjvm98119

Financial support: The present work was carried out with the support of the Coordination of Improvement of Higher Education Personnel - Brazil (CAPES - Coordenação de Aperfeiçoamento de Pessoal de Nível Superior) - Financing Code 001. The present work is financed by FAPERJ (development agency of the state Rio de Janeiro that encourage research) scholarship for one of the authors.

Conflict of interests: No conflict of interests declared concerning the publication of this article.

Received: October 07, 2018.

Accepeted: February 03, 2019

The study was carried out at the Laboratory of Experimental Chemotherapy in Veterinary Parasitology, Universidade Federal Rural do Rio de Janeiro - UFRRJ, Rio de Janeiro, RJ, Brasil.

\section{*Correspondence}

Mário dos Santos Filho

Instituto de Veterinária, Universidade Federal Rural do Rio de Janeiro - UFRRJ

Rodovia BR 465, Km 7, Campus Universitário,

Bairro Zona Rural

CEP 23897-000 - Seropédica (RJ), Brasil

E-mail: mariosantoscg@gmail.com

Copyright Santos Filho et al. This is an Open Access article distributed under the terms of the Creative Commons Attribution Non-Commercial License which permits unrestricted non-commercial use, distribution, and reproduction in any medium provided the original work is properly cited. 
intervalos de despolarizações ventriculares, ao eletrocardiograma (ECG), e fornece informações sobre a relação e contribuição do SNA na influência neural do controle da frequência cardíaca (Kleiger et al., 2005). O presente estudo tem por objetivo avaliar a VFC, por meio de exame eletrocardiográfico, em cães obesos, com Escore de Condição Corporal (ECC) 8/9 e 9/9, comparando com a VFC dos mesmos animais, após terapia com ração terapêutica no período de 6 meses.

Palavras-chave: balanço autonômico, obesidade, cães.

\section{Introduction}

The cardiac nerve regulation is influenced by obesity, but the autonomic response present in this disorder has not yet been elucidated. It has already been noticed that the $10 \%$ increase in body fat is able to lead to a decrease in parasympathetic action and an increase in heart rate (Rasmussen et al., 2012). However, at the same time as studies indicate the predominance of sympathetic tone in obesity, others have evidenced the decrease of this tone in humans (Talib et al. 2005; Carareto et al., 2007).

Several studies in humans report that obesity affects the autonomic function of the heart, generating a greater probability of heart failure and sudden death in these individuals. However, in dogs, there are still few studies on the cardiovascular effects of obesity (Malik et al., 1996; Kleiger et al., 2005).

The degree of obesity and the time in which the individual is in this condition are crucial for the appearance of cardiovascular changes in humans and probably in dogs (Atkins, 1999; Kleiger et al., 2005). In obese humans, a decrease in HRV is described, reflecting on an autonomic imbalance, with reduced parasympathetic modeling, which may or may not present an elevation of sympathetic tone (Minors \& O'Grady, 1997; Karason et al., 1999). It was found that after weight loss, several cardiac alterations were attenuated or reversed, especially when the individual performed physical activities (Karason et al., 1999; Pelosi et al., 2013).

In overweight adolescents, they were found to have an autonomic imbalance, caused by a decrease in SDNN* (standard deviation of all normal RR intervals) and total power (Guízar et al., 2005). In research with obese children, it was concluded that childhood obesity is associated with lower heart rate variability (Muralikrishnan et al., 2013).

Heart rate variability in dogs is widely described for the purpose of evaluating diseases such as endocardiosis, dilated cardiomyopathy and diabetes mellitus, relating them to changes in autonomic modulation (Liao et al., 2014). It is reported in a study in dogs, in which obesity was induced by dietary supplementation rich in saturated fat, lower parasympathetic control (Oliveira et al., 2012).

There are reports that morbid obesity in dogs did not change heart rate variability (Van Vliet et al., 1995; Pelosi et al., 2013). Other studies have verified that obese dogs presented alterations in the autonomic system, observing a decrease in heart rate variability when compared to dogs of ideal weight, suggesting a lower parasympathetic autonomic control in obese dogs (Mazini, 2011; Martins, 2016).

There is still little literature on the consequences of canine obesity on autonomic influence. Therefore, it is fundamental to understand the autonomic control under the heart of obese dogs and thus to reinforce the importance of the treatment of obesity and even more of the prevention of the same to improve their quality of life.

The objective of the present study was to evaluate the HRV by means of an electrocardiographic examination in obese dogs with Body Condition Score (BCS) 8/9 and 9/9, comparing with HRV of the same animals, after therapy with therapeutic ration in the period of 6 months.

\section{Material and methods}

The present study was licensed by the Committee on Ethics in the Use of Animals under the number 8892260517.

\section{Experimental design}

Initially, 20 Beagle dogs were selected from the bioterium of the University, where they lived under the same management conditions, in collective pens, with a maximum of six animals per enclosure, and were fed the same commercial ration in the quantities recommended by the 
manufacturer, once per day. According to the scale of Laflamme (1997), the animals were divided into the experimental groups: Control Group (GCt): 10 dogs with BCS 4-5 / 9 and Obese Group (GOb): 10 dogs with BCS 8-9/9.

The animals were then submitted to clinical examination, consisting of history / anamnesis and physical examination, using the means of clinical exploration (inspection, palpation, percussion and auscultation). At this moment, morphometric measurements were also performed to determine the percentage of body fat (\% BF). Blood samples were then collected for Complete Blood Count (CBC) and serum biochemistry (urea, creatinine, ALT and alkaline phosphatase). Animals considered free of comorbidities beyond obesity were then included in the study.

The study was performed in the electrocardiographic exam during five minutes, to calculate the Heart Rate Variability in the animals of both groups (GCt and GOb). GOb animals diagnosed as obese (BCS $=8$ or 9) were treated with Purina ${ }^{\circledR}$ Pro Plan ${ }^{\circledR}$ Overweight Management for a period of six months. After the treatment period, GOb animals were submitted to a new evaluation of BCS, \%BF and a new electrocardiographic exam, to calculate HRV after treatment.

\section{Body Condition Score (BCS)}

The quantitative analysis of the body condition score was performed according to the visual table proposed by Laflamme (1997). The animals were evaluated at the station on the ground, through inspection and palpation of the animal body in specific areas such as abdomen, thorax, cervical region and tail base, in order to verify the accumulation of fat.

\section{Calculation of Body Fat percentage (\% BF)}

The percentage of body fat was calculated by means of morphometric measurements such as the abdominal perimeter (AP) and the pelvic limb (PL) in centimeters. The measurement of the AP was realized holding the animal in a workstation on the table and with the aid of a tape measure, tracing a circumference around the abdomen of the animal from the midpoint between the wing of the ileum and the last thoracic vertebra, and the PL, by measuring the distance between the calcaneus tuberosity and the medial patellar ligament.

After the two measurements, their values were applied in the equation $\% \mathrm{BF}=(-1.7 \times \mathrm{PL})+(0.93 \times \mathrm{AP})+5$, to obtain the percentage of Body Fat (Burkholder \& Toll, 1997).

\section{Clinical examination}

For the clinical examination of the animals, historical data and anamnesis were collected with the person in charge of the maintenance of the animals, looking for compatible findings of endocrinopathic and cardiorespiratory diseases, as well as the morbid antecedents of each animal.

Initially, the animal remained free in the environment of the veterinary clinic for acclimatization and then was placed on top of the physical examination table, where it was contained in a gentle way by the person responsible for it.

The physical examination consisted of measuring vital parameters such as:1) heart rate through palpation of the femoral artery in one of the pelvic limbs; 2 ) respiratory rate by observation of thoracic breathing movements; 3) Capillary filling time by digital pressure in the gingival mucosa; 4) Inspection of the mucous membranes through observation of the oral and conjunctival mucosa; 5) rectal temperature using a mercury thermometer.

Then, in the continuity of the physical examination, a cough reflex evaluation was performed by means of discrete friction in the region of the cervical trachea. Cardiac auscultation was performed with the aid of a stethoscope beginning with the left-side tip shock region, locating the mitral focus, passing to the cranial and lateral region, locating the cardiac base, and the tricuspid focus on the right side. In all the focal points of auscultation the sounds and silences, as well as the rhythm were evaluated and furthermore the presence of murmurs were checked. Pulmonary auscultation in each hemithorax, right and left, was performed by means of a complete thoracic cavity scan with the aid of the stethoscope positioned in the intercostal spaces. Thoracic percussion was another method used during the clinical exploration, a digital-digital percussion in the intercostal spaces was performed. 
At the end of the physical examination, abdominal palpation was carried out to palpate the liver, spleen, stomach, kidneys and urinary vesicle.

\section{Blood sample collection and laboratory tests}

Puncture of the cephalic vein, lateral saphenous or external jugular vein was performed. Initially, the region to be punctured underwent antisepsis with cotton soaked in 70\% ethyl alcohol, and a blood sample of $5.0 \mathrm{~mL}$ was then collected by means of an intravenous infusion device (scalps) $23 \mathrm{G}$ or $22 \mathrm{G}$ needle attached to a $5.0 \mathrm{~mL}$ syringe.

The blood sample was divided into two tubes, with and without anticoagulant. Blood counts and serum biochemistry (alkaline phosphatase-ALP, alanine aminotransferase-ALT, urea and creatinine) were performed.

\section{Exclusion criteria}

The following exclusion criteria were used: the presence of clinical findings compatible with endocrinopathies or cardiorespiratory diseases; hematological changes detected in the hemogram; changes in serum biochemistry values; clinical findings that suggested the presence of any other disease, besides obesity.

\section{Electrocardiographic examination (ECG)}

The animals of the GCt and GOb groups were submitted to electrocardiographic (ECG) examination to determine the Heart Rate Variability (HRV). The ECG was performed using the InCardio ${ }^{\circledast}$ (InPulse Animal Health ${ }^{\odot}$ ) electrocardiograph device, with duration of 5 minutes, as recommended for HRV measurement (Martins, 2016). During the ECG, the dogs were removed from the kennel and acclimatized for 10 minutes in the room where the electrocardiographic examination was performed.

The animal was placed in the right lateral decubitus position and the electrodes for acquisition of Derivation II (DII) were then fixed as follows: 1) black electrode (RL) region of the knee of the right pelvic limb; 2) green electrode (LL) region of the knee of the left pelvic limb; 3) red electrode (RA) region of the elbow of the right thoracic limb; and 4) yellow electrode (LA) elbow region of the left thoracic limb (Tilley \& Smith Junior, 2008) (Figure 1).

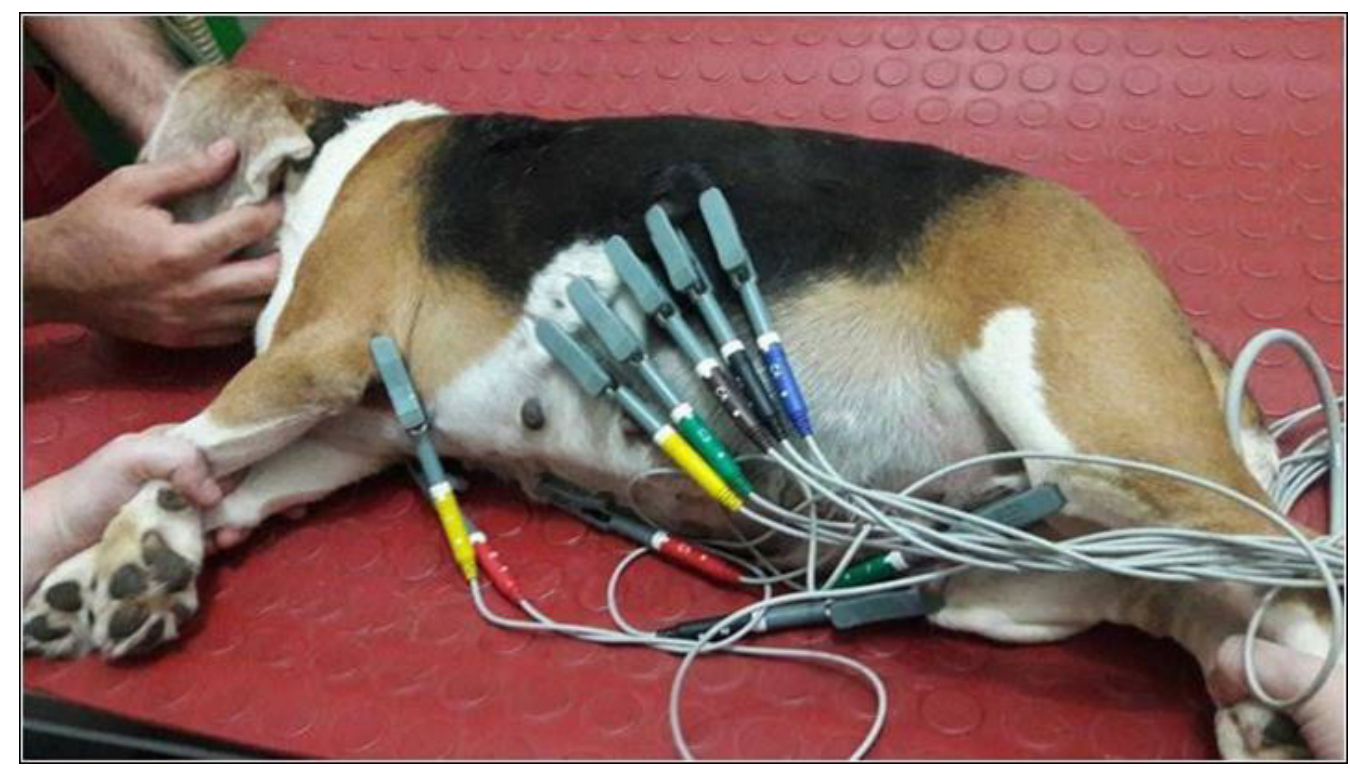

Figure 1. Animal in right lateral decubitus during continuous electrocardiography to record HRV. Source: Service of Cardiology and Respiratory Diseases - UFRRJ. 
For the analysis of the Heart Rate Variability (HRV), the variables of the time domain were: 1) mean NN, mean of all normal RR intervals of the exam; 2) SDNN, standard deviation of all normal RR intervals of the examination; and 3) rMSSD, square root of the sum mean of the squared difference of adjacent normal RR intervals throughout the examination. In addition, the minimum, mean and maximum heart rates (HR) were evaluated (Vanderlei et al., 2009).

\section{Obesity treatment}

After the electrocardiographic examination, the animals of the GOb group were transferred to individual stalls and underwent treatment with a low calorie Purina ${ }^{\circledR}$ ProPlan ${ }^{\circledR}$ Overweight Management - Obesity diet for a period of 2 months.

The Daily Energy Requirement (DER) in kilocalories (kcal) needed for weight loss and the daily amount of food to be consumed for each animal was defined for the treatment. For the RER (Resting Energy Requirement) the same value was defined as for the DER for weight loss, respecting for this purpose the calculation $\mathrm{DER}=\mathrm{RER} \times 1$. For the $\mathrm{RER}$ calculation, the RER formula was used $(\mathrm{kcal} /$ day $)=[30 \times($ weight $(\mathrm{kg})+70])$, where for the variable weight the animal's target weight was used as the current weight subtracted by 20\% (Jericó et al., 2014).

The daily amount of Purina ${ }^{\circledR}$ ProPlan ${ }^{\circledR}$ Overweight Management - Obesity to be offered to the animal in the treatment of obesity was stipulated according to the energy density of the food $(2,990 \mathrm{kcal} / \mathrm{kg}$ of dog food) and with the DER calculated for the animal. The amount of daily food was divided into two equal parts and offered twice a day to the animals.

The treatment lasted six months, and throughout this period physical activities and recreation were carried out with all animals at least twice a week.

For follow-up of treatment progression, clinical reassessment of the animals was performed every quarter, as well as their weighing and morphometric measurement. At the same time, information about the adaptation and acceptance of the animal to the new diet was collected and, if necessary, adjustments were made to the calculations.

\section{Post-treatment evaluation}

After the stipulated period of two months of treatment, the animals of the GOb group underwent a new weight evaluation, body fat percentage calculation and Body Condition Score quantification. A new electrocardiographic exam was also performed to evaluate the Heart Rate Variability and compared to before treatment.

All re-evaluations followed the same criteria established at the time of before treatment.

\section{Statistical analysis}

All variables of the present study were submitted to descriptive statistics and presented on the form of mean and standard deviation or median and minimum and maximum values depending on their normal distribution or not, respectively.

The variables were also subjected to the Shapiro-Wilk normality test. Variables that behaved in normal distribution had their means compared by the Student's T test, while variables that behaved in a non-parametric manner had their means compared by the Mann Whitney test.

For all tests, the level of significance was $5 \%$ and the statistical treatment was performed through the use of BioEstat ${ }^{\circledR}$ software version 5.0 (Mamirauá Institute).

\section{Results}

The 10 dogs selected by the Body Condition Score (BCS) 4 or 5/9 for the control group (GCt) were between 1 and 6 years old $\left[\mathrm{X}^{2}=4 ; \mathrm{CV}=51.04 \%\right]$. In regard to sex, two animals were females and eight animals were males $(\overline{\mathrm{x}}=7.2 ; \mathrm{p}=0.0253)$, with differences between the sexes in the composition of the group. None of the animals in this group were castrated.

The weight of the GCt animals ranged from 9.6 to $12.8 \mathrm{~kg}(\overline{\mathrm{x}}=11.25 ; \mathrm{SD}=1.15 ; \mathrm{CV}=10.27 \%)$, while the percentage of Body Fat (BF) ranged from 17.2 and 30.90\% ( $\bar{x}=22.79 ; \mathrm{SD}=4.41 ; \mathrm{CV}=19.36 \%$ ).

Regarding GOb, the ten animals from the first phase of the study were maintained in the second phase so that their Heart Rate Variability indices could be used in the comparison after 
treatment. The selected dogs had 8 or 9/9 BCS, and were between 2 and 8 years old $[\bar{x}=6(2.8)$; $\mathrm{CV}=31.43 \%]$. Regarding sex, GOb was composed of three males, all castrated and seven females, of which only one was castrated $\left(\mathrm{X}^{2}=3.2 ; \mathrm{p}=0.1797\right)$, not being detected any difference between the sexes in the composition of the group.

The weight of GOb animals varied between 13.4 and $24.2 \mathrm{~kg}(\overline{\mathrm{x}}=17.2 ; \mathrm{SD}=3.68$ and $\mathrm{CV}=21.61 \%)$, while the percentage of Body Fat (\% BF) ranged from 31.74 and $56.53 \%(\overline{\mathrm{x}}=41.2$; $\mathrm{SD}=6.52$; $\mathrm{CV}=15.82 \%$ ).

GOb was also constituted in the first phase of the study; however, one animal had to be excluded from the original group, composed of 11 animals, in view of the fact that it had developed clinical signs compatible with endocrinopathy.

After the treatment with the Purina ${ }^{\circledast}$ Low Calorie Treatment Pro Plan ${ }^{\circledast}$ Overweight Management - Obesity, the weight of GOb animals significantly reduced $(t=6.5 ; \mathrm{p}<0.0001)$ to values between 11.8 and $20.0 \mathrm{~kg}(\overline{\mathrm{x}}=14.7 ; \mathrm{SD}=2.85 ; \mathrm{CV}=19.42 \%)$ at 2 months after beginning of treatment, and to 10.25 and $17 \mathrm{~kg}(\overline{\mathrm{x}}=13.54 ; \mathrm{SD}=2.34 ; \mathrm{CV}=18.61 \%)$ after six months of treatment (Figure 2).

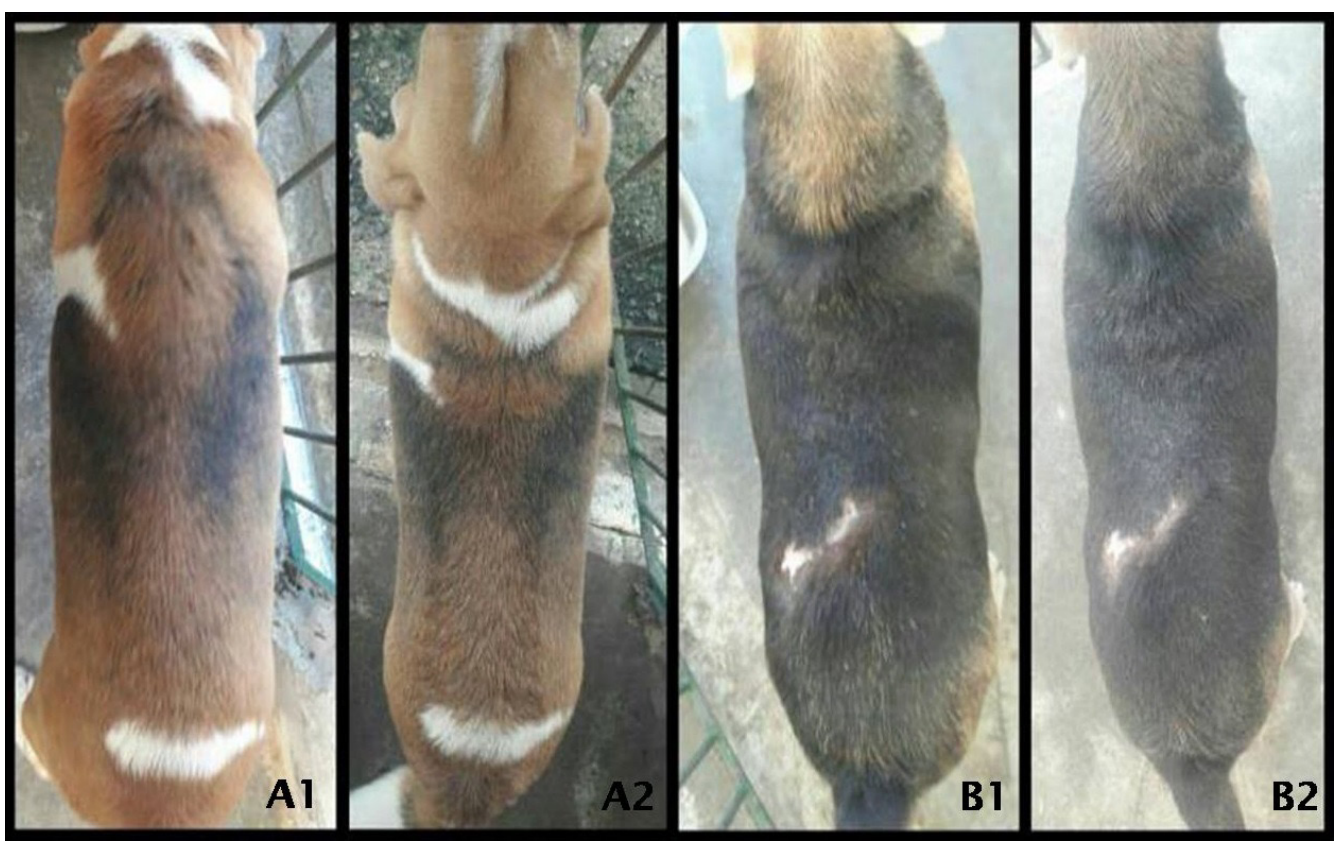

Figure 2. Dorsal view of two Beagle dogs included in the low-calorie diet before (A1 and B1) and after six months before of the treatment (A2 and B2). Source: Service of Cardiology and Respiratory Diseases - UFRRJ.

Considering the \%BF, after treatment, this index presented a significant drop $(t=11.5 ; \mathrm{p}<0.0001)$ to values between 21.05 and $41.65 \%(\bar{x}=28.32 ; \mathrm{SD}=6.06 ; \mathrm{CV}=21.39 \%)$.

The HRV study consisted of comparing the indexes of this tool in the time domain (SDNN, SDANN, rMSSD) and the minimum, average and maximum heart rates (HR) between GOb before and after treatment with the low calorie Purine ${ }^{\circledast}$ Pro Plan ${ }^{\circledast}$ Overweight Management - Obesity, besides comparing the same indexes between GOb after GC treatment (Figure 3).

The analysis of HRV in the GCt presented values of SDNN of 91.14 \pm 40.02 , SDANN of $549.80 \pm 75.32$ and rMSSD of $117.50 \pm 44.71$. The GOb had SDNN values of $149.50 \pm 76.65$ before treatment, and $138.90 \pm 41.56$ after six months; SDANN of $605.02 \pm 110.97$ before treatment, and $516.60 \pm 122.56$ after six months; and rMSSD of $217.10 \pm 109.74$ before treatment, and $156.77 \pm 56.97$ after six months.

The maximum and average HRs presented very discrete oscillations between the groups. On the other hand, the minimum HR increased after treatment in GOb. However, this increase was not confirmed statistically. When the minimum HR of the GCt was compared to the GOb 


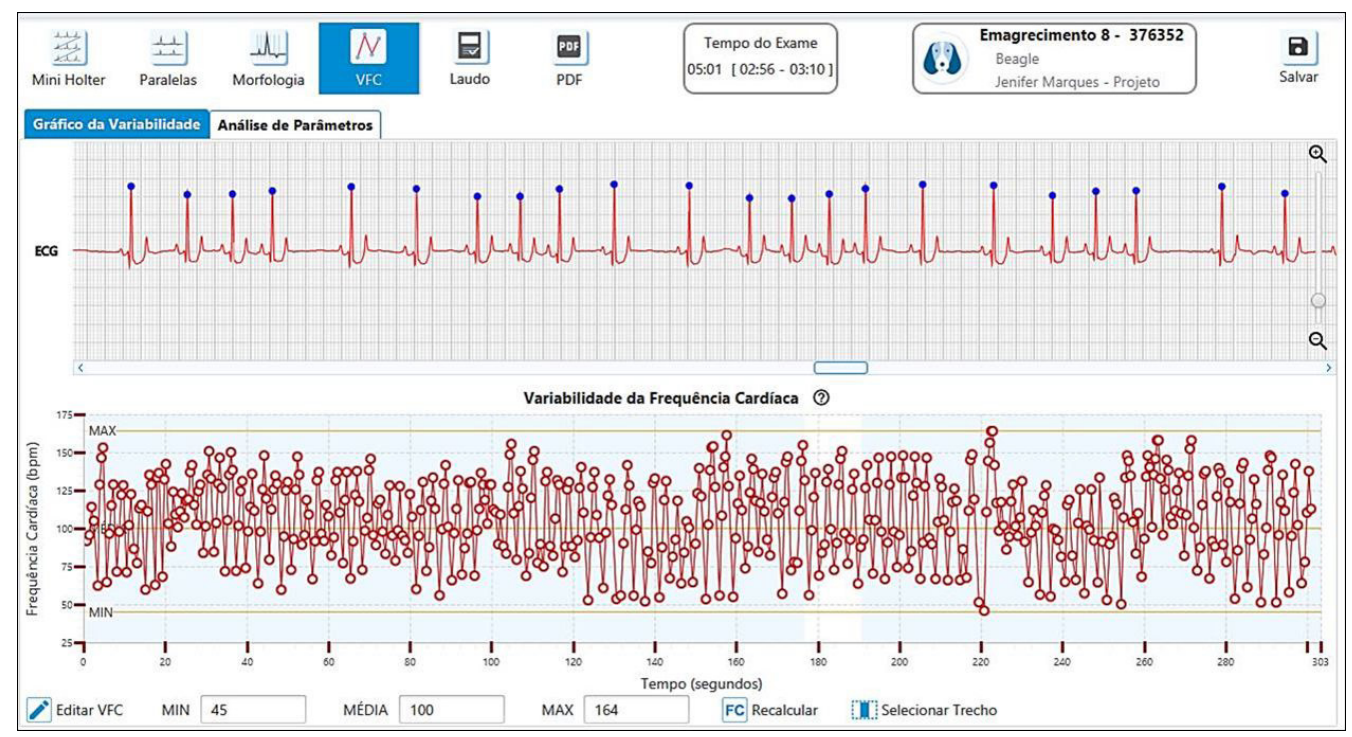

Figure 3. Heart rate variability (Variabilidade da frequência cardíaca) chart, showing R-R intervals, minimum, medium and maximum heart rate. Source: Service of Cardiology and Respiratory Diseases - UFRRJ.

before treatment, it was observed that this difference was greater $(t=2.745 ; \mathrm{p}=0.0073)$ than the difference found between GCt and GOb after six months of treatment ( $t=2.821 ; \mathrm{p}=0.0395)$.

Through electrocardiographic examination, sinus arrhythmia can be observed before treatment in nine of the ten GOb dogs, and five of these animals had associated cardiac arrest rhythm or sinus block. After treatment, eight animals of this group presented sinus arrhythmia on the electrocardiographic record, and only one of them maintained the occurrence of sinus arrest or block and another animal presented a ventricular leak in the face of a sinus pause. The remaining two animals in this group at the time of treatment presented sinus rhythm (Figure 4).

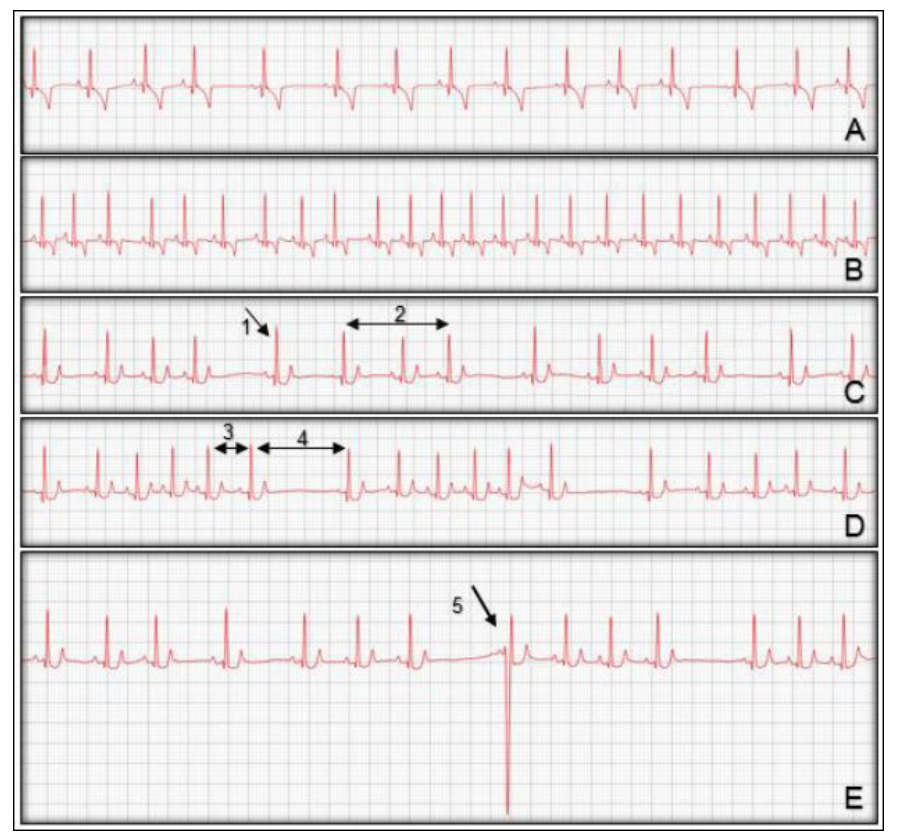

Figure 4. Electrocardiographic tracing in D2 lead, $\mathrm{N}$ sensitivity $(10 \mathrm{~mm} / \mathrm{mV})$, Speed $25 \mathrm{~mm} / \mathrm{s}$. A: Sinus rhythm; B: Sinus tachycardia; C: Sinus arrhythmia. The arrow 1 demonstrates a decrease in heart rate at the time of expiration and arrow 2 increases at the time of inspiration; D: Sinus arrhythmia with presence of "Sinus Arrest" as illustrated in arrow 4, with the interval R-R greater than twice the previous R-R interval (arrow 3); E: Sinus arrhythmia with presence of Ventricular Escape after a Stop or Sinus Block (Arrow 5). 
In the animals of the GCt, sinus rhythm can be observed in the electrocardiographic record of six animals, sinus tachycardia in two animals and sinus arrhythmia in the remaining two animals.

\section{Discussion}

The experimental design of the present study aims the comparison of Heart Rate Variability (HRV) indices between animals under normal nutritional conditions and obese animals, as well as how much the treatment of obesity with the Purina ${ }^{\circledast}$ Low Calorie Therapy ${ }^{\circledast}$ Pro Plan ${ }^{\circledast}$ Overweight Management - Obesity could reverse the possible autonomic imbalance on the heart, caused by obesity (Kleiger et al., 2005).

In order to do so, the adoption of the Body Condition Score (BCS) as an inclusion criterion was necessary, which, despite being a poorly sensitive method for assessing the dog's nutritional status, is easy to apply and has been widely used in the clinical routine for the diagnosis of obesity (Laflamme, 2006).

As BCS was the first selection criterion for the animals that would compose the experimental groups, it was necessary to flexibilize the other data of the animals, such as age, sex and reproductive status. For this reason, the age of the animals that constituted both the Control Group (GCt) and the Obese Group (GOb) was not precisely homogeneous, which can be verified by its coefficients of variation above the values recommended as ideal for samples with low variability (Sampaio, 2002).

The sex distribution of the animals included in the study also did not maintain a homogeneous pattern, and a statistical difference between the sexes in the GCt could be detected. Again, due to the selection criterion of the animals being the ECC evaluation, it was inevitable that in order to obtain the sufficient " $n$ " sample to allow the statistical analyzes pertinent to the study. On the other hand, the exclusive use of a single breed of dogs in the composition of the experimental groups significantly solidifies the control of the experiment and balances the criteria of homogeneity in relation to those not attended, due to the standardization of the body conformation, as well as the behavior when facing stress situations induced in the experimentation (Sampaio, 2002; Laflamme, 2006).

The use of animals from an experimental kennel allowed the control of the extrinsic factors involved in obesity. The fact that the animals are kept under the same environmental and management conditions, allowed the strict monitoring of the treatment, without risks of error in the quantity of feed offered, in the time of supply and mainly in the supply of other foods, situations that are routinely addressed in the literature when considering possible failures in the treatment of obesity (Jericó et al., 2014).

The clinical examination of the animals confirming only the commitment for obesity in the absence of other diseases and the elimination of hematological alterations and serum biochemistry, before inclusion in the study, allowed the clinical exclusion of diseases that could be influencing obesity, diseases that could harm the effectiveness of treatment and diseases that could influence HRV (Courcier et al., 2010).

The success of the treatment, although short lived (six months), was evidenced in the comparison of the weight of the animals and the percentage of Body Fat before and after the established period, which demonstrated a significant reduction, without extrapolating the limits recommended for a healthy weight loss, without exposing the animal to stress by negative energy balance, taking into account the gradual reduction of feed (Verkest, 2014).

Some studies consider that healthy body weight loss should be 1 to $3 \%$ of the initial weight of the treatment per week (Jericó et al., 2014). In the present study, the mean weight loss percentage of the treated animals was $13.27 \%$ at 2 months of treatment and $20.52 \%$ at 6 months, and considering the percentage of individual loss divided equally by the number of weeks of treatment, we reach the weekly average of $1.66 \%$ at 2 months and $0.76 \%$ of body weight, which shows that the loss is higher at the beginning and has a tendency to decrease over time. However, even in the face of this reduction, the weight of GOb animals did not approximate GCt values ( $t=-3.54 ; \mathrm{p}=0.0023$ ) (Verkest, 2014).

The \%BF estimate was useful for monitoring the treatment of the animals, although several limitations are attributed to this method, such as hidden fat or the limitation of the technique. It was possible to determine that the mean percentage reduction of the \% $\mathrm{BF}$ throughout the 
treatment was $12.88 \%$, suggesting the maintenance of the lean mass while there was reduction of the fat mass, based on the morphometric parameters with fat loss (Batistela \& Domingues, 2005). These post-treatment values, although reduced, also did not approximate GCt values $(\mathrm{t}=-2.33 ; \mathrm{p}=0.0157)$.

Controlled studies that allow the comparison of the animal with itself, make morphometric methods a little more sensitive, despite the approach of specific areas of the body, which do not necessarily reflect the real magnitude of obesity (Sampaio, 2002).

The first phase of this study consisted of comparing HRV indices between animals with normal BCS (4 and 5/9) and animals with BCS that categorize obesity (8 and 9/9) and, in this step, a different response from the few reports in literature can be detected, which assume lower HRV for obese animals by increasing sympathetic tone or reducing parasympathetic tone (Pelosi et al., 2013).

Although not all indexes were statistically confirmed to be larger in obese animals, the rMSSD index was significantly higher in this group, and because of its mathematical extrapolation the use of the square root of the sum of the squares is considered one of the most reliable in the evaluation of the parasympathetic activity, interpreting that the higher this index the greater the autonomic balance on the heart (Pumprla et al., 2002; Acharya et al., 2006; Vanderlei et al., 2009).

In this context, the objective was to evaluate whether the treatment of obesity with a hypocaloric diet could return the HRV index to levels similar to those of animals under normal nutritional conditions (Acharya et al., 2006).

After a short period of time for treatment of obesity, the evaluation of three HRV indexes in the time domain showed a tendency to reduce them when compared to the moment before treatment. This pattern was confirmed statistically with the findings of HRV. In GOb, there was no difference in SDNN before treatment and after 6 months. In the GCt, there was a difference in relation to the GOb before treatment $(U=27 ; p=0.0410)$. Analyzing the SDANN, there was no difference between the two groups in the two moments, as well as between the moments in the GOb.

Regarding rMSSD, there was no difference between GOb before and GOb after 6 months of treatment. However, when comparing GOb with GCt, there was difference before treatment $(\mathrm{U}=22 ; \mathrm{p}=0.0171)$, and this difference was not confirmed after treatment, at which time the mean of this variable reduced to values similar to GCt. Thus, after a short period of time for treatment of obesity (Courcier et al., 2010) the evaluation of these three indices showed a tendency to reduce when compared to the moment before treatment (Table 1).

Table 1. HRV: Heart Rate Variability; SDNN: Standard deviation of all RR intervals; SDANN: Standard deviation of the mean NN intervals obtained every 5 minutes; rMSSD: Square root of the mean between the squared differences of the consecutive NN intervals; GOb BT: Obese Group Before Treatment; Gob PT: Obese Group Post-Treatment of 6 months; GCt: Control Group; HR: Heart Rate; SD: Standard Deviation; ms: milliseconds; BPM: beats per minute. Different letters ("a" and "b") along the same line indicate a significant difference at level of $5 \%$.

\begin{tabular}{cccccc}
\hline \multirow{2}{*}{ Variables of HRV } & GOb BT & & GOb PT & & GCt \\
\cline { 2 - 3 } \cline { 5 - 6 } & Mean \pm SD & & Mean \pm SD & & Mean \pm SD \\
\hline SDNN (ms) & $149,50 \pm 76,65^{\mathrm{a}}$ & & $138,90 \pm 41,56^{\mathrm{a}}$ & & $91,14 \pm 40,02^{\mathrm{b}}$ \\
SDANN (ms) & $605,02 \pm 110,97$ & & $516,60 \pm 122,56$ & & $549,80 \pm 75,32$ \\
rMSSD (ms) & $217,10 \pm 109,74^{\mathrm{a}}$ & & $156,77 \pm 56,97^{\mathrm{a}}$ & & $117,50 \pm 44,71^{\mathrm{b}}$ \\
Minimal HR (BPM) & $50,35 \pm 13,90^{\mathrm{a}}$ & & $58,10 \pm 15,80^{\mathrm{a}}$ & & $70,50 \pm 16,12^{\mathrm{b}}$ \\
Mean HR (BPM) & $102,80 \pm 18,80$ & & $103,30 \pm 15,02$ & & $110,80 \pm 16,62$ \\
Maximum HR (BPM) & $167,50 \pm 34,94$ & & $170,20 \pm 16,28$ & & $164,50 \pm 21,43$ \\
\hline
\end{tabular}

This pattern was confirmed statistically in rMSSD and SDNN indices. The reduction of SDNN, since this is an index obtained from long-term records, does not specify whether what occurred was a reduction of parasympathetic activity or increase of sympathetic activity. However, its association with rMSSD reduction, which translates parasympathetic activity by analyzing 
adjacent RR intervals (Malik et al., 1996), may indicate that the treatment of obesity reduced parasympathetic activity.

These indexes didn't return to values statistically similar to those of the control group, suggesting that the short period of treatment was not enough to normalize the autonomic activity on the heart (Malik et al., 1996; Acharya et al., 2006; Martins 2016).

The findings of the minimal heart rate with the same behavior in the HRV index statistics reinforce that obese animals are more influenced by the parasympathetic activity. The minimal heart rate also increased in the GOb after treatment, but it didn't reach the similar values of the GCt animals (Martins, 2016).

Studies in obese humans indicate that parasympathetic stimulation from controlled deep breathing does not trigger response in the HRV expected by increased vagal tone, as in healthy individuals (Acharya et al., 2006).

With the results obtained in the present study, it is possible to infer that the imbalance in the autonomic activity due to obesity in dogs is not the same as in humans and that a greater understanding of this regulation in these animals is necessary. Especially when considering their physiological vagotonia which causes the vast majority of dogs to present sinus arrhythmia on the electrocardiographic record (Goldberger, 1999).

There are many controversial studies on obesity versus autonomic activity on the heart, suggesting a reduction in parasympathetic activity (Farah et al., 2013), reduction of both activities (sympathetic and parasympathetic) (Karason et al., 1999) and even suggesting that obesity has no influence over the regulation of the heart (Zoran, 2010).

Although the actual pathophysiological mechanism with which obesity in dogs analyzed in this study increases parasympathetic activity, efforts should be directed toward studies with larger " $n$ " samples and with increasingly effective controls, and which could be developed for the best elucidation of this issue. (Sampaio, 2002).

Parallel to the results of HRV indices, the electrocardiographic record allowed the preponderant heart rhythm to be identified over the five minutes. The pre-treatment GOb presented predominantly rhythms induced by high parasympathetic activity, such as sinus arrhythmia and sinus arrest or blockade (Tilley \& Smith Junior, 2008), which occur mainly through the direct action of acetylcholine release on the muscarinic receptors of the sinus node (Martins, 2016). After treatment, sinus arrest or blockade reduced to occurrence in only two animals, reinforcing the hypothesis of reduction of parasympathetic activity during weight loss (Kleiger et al., 2005).

When considering the cardiac rhythms recorded in the GCt, it is observable that even the sinus arrhythmia that is considered physiological in the dog because of its vagotonia (Tilley \& Smith Junior, 2008) occurred in only two animals. Considering that even after acclimatization of 10 minutes, the physical restraint for the examination can be considered a stressor stimulus to the animal, triggering reduction of the parasympathetic activity and/or the increase of the sympathetic activity. It would be reasonable to not wait for the occurrence of the rhythms induced by the vagal tonus (Goldberger, 1999; Pascon, 2009; Muralikrishnan et al., 2013).

On the other hand, considering that obese animals suffered the same stress conditions and didn't fail to present rhythms induced by vagal tonus, it endorses the suggestion that obesity can increase parasympathetic activity or only inhibit its suppression in the face of stress (Penttilä et al., 2001).

The high heart rate variability is associated by many scholars with the balance of autonomic regulation over the heart (Kleiger et al., 2005; Vanderlei et al., 2009). However, it should be pointed out that in species such as the dog in which there is already a predominance of the activity parasympathetic, this tool must be interpreted cautiously in the face of obesity (Mazini, 2011; Martins, 2016).

It should be considered that from the moment that an obese dog has higher HRV than normal dogs, somehow this disease is acting exaggeratedly on the autonomic balance (Minors \& O'Grady, 1997; Liao et al., 2014).

\section{Conclusion}

The low-calorie diet program achieves approximately $10 \%$ and $20 \%$ of weight reduction after two and six months, respectively. 
Theindex of body fat percentage, although described as a poorly sensitive method for diagnosing obesity, is detectably reduced during weight loss.

Obesity increases HRV by increasing parasympathetic activity in the autonomic regulation of the heart.

Obese animals are exposed to rhythm disturbances linked to increased parasympathetic activation over cardiac batmotropism.

\section{Acknowledgments}

The present work was carried out with the support of the Coordination of Improvement of Higher Education Personnel - Brazil (CAPES - Coordenação de Aperfeiçoamento de Pessoal de Nível Superior) - Financing Code 001. The present work is financed by FAPERJ (development agency of the state Rio de Janeiro that encourage research) scholarship for one of the authors. Thanks to Nestlé Purina ${ }^{\circledR}$ for the inputs and funding of the Young Veterinary Program for the authors. We thank the Laboratory of Experimental Chemotherapy in Veterinary Parasitology - UFRRJ (Universidade Federal Rural do Rio de Janeiro), for the support.

\section{References}

Acharya, U. R., Joseph, K. P., Kannathal, N., Lim, C. M., \& Suri, J. S. (2006). Heart rate variability: a review. Medical \& Biological Engineering \& Computing, 44(12), 1031-1051. http://dx.doi.org/10.1007/s11517-006-0119-0. PMid:17111118.

Atkins, C. E. (1999). Cardiac manifestations of systemic and metabolic disease. In: P. P. Fox, D. Sisson, N. S. Moise (Eds.), Textbook of canine and feline cardiology: principles and clinical practice (2nd ed., pp. 757-780). Philadelphia: WB Saunders.

Batistela, C. M., \& Domingues, J. L. (2005). Aspectos nutricionais e de manejo na obesidade em cães. Nutritime, 2(3), 201-205.

Burkholder, W. J., \& Toll, P. W. (2000). Obesity. In M. S. Hand, C. D. Thatcher, R. L. Remillard, P. Roudebush, \& B. J. Novotny, (Eds.), Small animal clinical nutrition (4th ed., pp. 401-430). Topeka: Mark Morris Institute.

Carareto, R., Sousa, M. G., Zacheu, J. C., Aguiar, A. J. A., \& Camacho, A. A. (2007). Variabilidade da freqüência cardíaca em cães anestesiados com infusão contínua de propofol e sufentanil. Arquivo Brasileiro de Medicina Veterinária e Zootecnia, 59(2), 329-332. http://dx.doi.org/10.1590/S0102-09352007000200009.

Courcier, E. A., Thomson, R. M., Mellor, D. J., \& Yam, P. S. (2010). An epidemiological study of environmental factors associated with canine obesity. The Journal of Small Animal Practice, 51(7), 362-367. http://dx.doi. org/10.1111/j.1748-5827.2010.00933.x. PMid:20402841.

Farah, B. Q., Prado, W. L., Tenório, T. R. S., \& Ritti-Dias, R. M. (2013). Relação entre variabilidade da frequência cardíaca e indicadores de obesidade central e geral em adolescentes obesos normotensos. Einstein (Sao Paulo), 11(3), 285-290. http://dx.doi.org/10.1590/S1679-45082013000300005. PMid:24136753.

Goldberger, J. J. (1999). Sympathovagal balance: how should we measure it? The American Journal of Physiology, 276(4), 1273-1280. http://dx.doi.org/10.1152/ajpheart.1999.276.4.H1273. PMid:10199852.

Guízar, J. M., Ahuatzin, R., Amador, N., Sánchez, G., \& Romer, G. (2005). Heart autonomic function in overweight adolescents. Indian Pediatrics, 42(5), 464-469. PMid:15923693.

Jericó, M. L. F., Lorenzini, F., \& Kanayama, K. (2014). Manual de obesidade canina e felina (Apoio Nestlé Purina). São Paulo: Associação Brasileira de Endocrinologia Veterinária.

Karason, K., Mølgaard, H., Wikstrand, J., \& Sjöström, L. (1999). Heart rate variability in obesity and the effect of weight loss. The American Journal of Cardiology, 83(8), 1242-1247. http://dx.doi.org/10.1016/S0002 9149(99)00066-1. PMid:10215292.

Kleiger, R. E., Stein, P. K., \& Bigger Junior, J.T. (2005). Heart rate variability: measurement and clinical utility. Annals of Noninvasive Electrocardiology, 10(1), 88-101. http://dx.doi.org/10.1111/j.1542-474X.2005.10101.x. PMid:15649244

Laflamme, D. (1997). Development and validation of a body condition score system for dogs: a clinical tool. Canine Practice, 22(1), 10-11.

Laflamme, D. P. (2006). Understanding and managing obesity in dogs and cats. Veterinary Clinics: Small Animal Practice, 36(6), 1283-1295, vii. PMid:17085235.

Liao, D., Rodriguez-Colon, S. M., He, F., \& Bixler, E. O. (2014). Childhood obesity and autonomic dysfunction: risk for cardiac morbidity and mortality. Current Treatment Options in Cardiovascular Medicine, 16(10), 342-355. http://dx.doi.org/10.1007/s11936-014-0342-1. PMid:25143120.

Malik, M., Bigger, J. T., Camm, A. J., Kleiger, R. E., Malliani, A., Moss, A. J., Schwartz, P. J., \& Task Force of the European Society of Cardiology and the North American Society of Pacing and Electrophysiology (1996). Heart rate variability: standards of measurement, physiological interpretation, and clinical use. European Heart Journal, 17(3), 354-381. http://dx.doi.org/10.1093/oxfordjournals.eurheartj.a014868. PMid:8737210.

Martins, N. C. (2016). Análise da variabilidade da frequência cardíaca em cães obesos (Dissertação de mestrado). Universidade de Brasília, Brasília. 
Mazini, A. M. (2011). Avaliação da ocorrência de arritmias e da variabilidade da frequência cardíaca em cães obesos pelo método Holter. (Dissertação de mestrado) Universidade de São Paulo, São Paulo. http://dx.doi. org/10.11606/D.10.2011.tde-25092012-112844.

Minors, S. L., \& O'Grady, M. R. (1997). Heart rate variability in the dog; Is it too variable? Canadian Journal of Veterinary Research, 61(2), 134-144. PMid:9114965.

Muralikrishnan, K., Balasubramanian, K., Ali, S. M. J., \& Rao, B. V. (2013). Poincare plot of heart rate variability: an approach towards explaining the cardiovascular autonomic function in obesity. Indian Journal of Physiology and Pharmacology, 57(1), 31-37. PMid:24020096.

Oliveira, M. S., Muzzi, R. A., Araújo, R. B., Muzzi, L. A., Ferreira, D. F., Nogueira, R., \& Silva, E. F. (2012). Heart rate variability parameters of myxomatous mitral valve disease in dogs with and without heart failure obtained using 24-hour Holter electrocardiography. The Veterinary Record, 170(24), 622-627. http://dx.doi.org/10.1136/ vr.100202. PMid:22645158.

Pascon, J. P. E. (2009). Estudo da variabilidade da frequência cardíaca em cães (Tese de doutorado). Universidade Estadual Paulista, Jaboticabal.

Pelosi, A., Rosenstein, D., Abood, S. K., \& Olivier, B. N. (2013). Cardiac effect of short-term experimental weight gain and loss in dogs. The Veterinary Record,172(6), 153-153. http://dx.doi.org/10.1136/vr.100178. PMid:23292946.

Penttilä, J., Helminen, A., Jartti, T., Kuusela, T., Huikuri, H. V., Tulppo, M. P., Coffeng, R., \& Scheinin, H. (2001). Time domain, geometrical and frequency domain analysis of cardiac vagal outfow: effects of various respiratory patterns. Clinical Physiology (Oxford, England), 21(3), 365-376. http://dx.doi.org/10.1046/j.1365-2281.2001.00337.x. PMid:11380537.

Pumprla, J., Howorka, K., Groves, D., Chester, M., \& Nolan, J. (2002). Functional assessment of heart rate variability: physiological basis and practical applications. International Journal of Cardiology, 84(1), 1-14. http://dx.doi. org/10.1016/S0167-5273(02)00057-8. PMid:12104056.

Rasmussen, C. E., Falk, T., Zois, N. E., Moesgaard, S. G., Häggström, J., Pedersen, H. D., Åblad, B., Nilsen, H. Y., \& Olsen, L. H. (2012). Heart rate, heart rate variability, and arrhythmias in dogs with myxomatous mitral valve disease. Journal of Veterinary Internal Medicine, 26(1), 76-84. http://dx.doi.org/10.1111/j.1939-1676.2011.00842.x. PMid:22151356.

Sampaio, I. (2002). Estatística aplicada a experimentação animal (2. ed.). Belo Horizonte: Fundação de Estudo e Pesquisa em Medicina Veterinária e Zootecnia.

Talib, S. H., Mulay, P. Y., \& Patil, A. N. (2005). Twenty-four Hour Ambulatory ECG-Holter Monitoring and Heart Rate Variability in Healthy Individuals. Journal Indian Academy of Clinical Medicine, 6(2), 136-141.

Tilley, L. P., \& Smith Junior, F. W. K. (2008). Consulta veterinária em 5 minutos - espécies canina e felina (3. ed.). Barueri: Manole.

Van Vliet, B. N., Hall, J. E., Mizelle, H. L., Montani, J. P., \& Smith Junior, M. J. (1995). Reduced parasympathetic control of heart rate in obese dogs. The American Journal of Physiology, 269(2), 629-637. http://dx.doi.org/10.1152/ ajpheart.1995.269.2.H629. PMid:7653627.

Vanderlei, L. C. M., Pastre, C. M., Hoshi, R. A., Carvalho, T. D., \& Godoy, M. F. (2009). Noções básicas de variabilidade da frequência cardíaca e sua aplicabilidade clínica. Revista Brasileira de Cirurgia Cardiovascular: Orgão Oficial da Sociedade Brasileira de Cirurgia Cardiovascular, 24(2), 205-217. http://dx.doi.org/10.1590/S010276382009000200018. PMid:19768301.

Verkest, K. R. (2014). Is the metabolic syndrome a useful clinical concept in dogs? A review of the evidence. Veterinary journal (London, England: 1997), 199(1), 24-30. http://dx.doi.org/10.1016/j.tvjl.2013.09.057. PMid:24246648.

Zoran, D. L. (2010). Obesity in dogs and cats: a metabolic and endocrine disorder. The Veterinary Clinics of North America. Small Animal Practice, 40(2), 221-239. http://dx.doi.org/10.1016/j.cvsm.2009.10.009. PMid:20219485. 